Revista Ambientale

Revista da Universidade Estadual de Alagoas/UNEAL

e-ISSN 2318-454X, Ano 13, Vol. 13 (3), 2021

https://doi.org/10.48180/ambientale.v13i3.313

\title{
Educação ambiental na percepção de professores e alunos do ensino fundamental
}

\section{Environmental education in the perception of elementary school teachers and students}

\section{${ }^{(1)}$ Catiana Gomes dos SANTOS; ${ }^{(2)}$ Rosineide Nascimento da SILVA.}

\author{
${ }^{(1)}$ ORCID: https://orcid.org/0000-0001-8032-3958; Graduanda em Ciências Biológicas pela Universidade \\ Estadual de Alagoas, cacaugomes642@gmail.com \\ (2)ORCID: https://orcid.org/0000-0002-0197-2309; Professora do Curso de Ciências Biológicas da \\ Universidade Estadual de Alagoas, mestra em Ecologia e Conservação, rosineideg7@ gmail.com
}

Resumo - O principal ambiente para a promoção da Educação Ambiental (EA) são as escolas devido a uma série de fatores, pois presume-se que essa temática seja abordada com maior frequência, assim como práticas de intervenção e sensibilização envolvendo os discentes. Devido a importância da EA como uma ferramenta amplamente utilizada como via de sensibilização, objetivou-se com este estudo relatar a aplicação da EA na rotina de docentes e discentes da educação básica. A intervenção foi realizada em uma escola municipal do município de São Sebastião - AL, em 2019. A coleta de dados foi executada por meio da aplicação de dois questionários para os discentes e docentes, contendo questões de natureza objetiva e subjetiva. Os resultados dos questionários foram tabulados e analisados por meio do Software Microsoft Office Excel Professional Plus. Tanto os discentes, quanto os docentes participantes da intervenção possuíam conhecimentos ligados a importância, a implementação e as formas de obtenção de informações sobre EA e temas relacionados. Porém, se faz necessário mais abordagens neste âmbito, assim como o monitoramento destas atividades de intervenção, para que sejam aplicadas no cotidiano escolar, podendo assim, realizar mudanças no cotidiano dos discentes da instituição.

Palavras-chave: educação básica. Intervenção. práticas de ensino.

\begin{abstract}
The main environment for the promotion of Environmental Education (EE) are schools due to a number of factors, as it is assumed that this issue is addressed more frequently, as well as intervention and awareness practices involving students. Due to the importance of EE as a widely used tool as a way of raising awareness, the aim of this study was to report the application of EE in the routine of teachers and students of basic education. The intervention was carried out in a municipal school in the city of São Sebastião - AL, in 2019. Data collection was performed through the application of two questionnaires for students and teachers, containing questions of an objective and subjective nature. The results of the questionnaires were tabulated and analyzed using the Microsoft Office Excel Professional Plus Software. Both the students and the professors participating in the intervention had knowledge related to the importance, implementation and ways of obtaining information about EE and related topics. However, it is necessary more approaches in this area, as well as the monitoring of these intervention activities, so that they are applied in the daily school life, thus being able to make changes in the daily life of the institution's students.
\end{abstract}


Revista Ambientale

Revista da Universidade Estadual de Alagoas/UNEAL

e-ISSN 2318-454X, Ano 13, Vol. 13 (3), 2021

https://doi.org/10.48180/ambientale.v13i3.313

Keywords: basic education. intervention. teaching practices.

\section{Introdução}

Promover o ensino da Educação Ambiental tem sido uma preocupação constante ao longo de vários processos de ensino, pois por meio dela se deu início a uma consolidação da consciência que o homem depende dos recursos que a natureza fornece e, ao mesmo tempo, tem mostrado que esses recursos são limitados (PADIAL, 2013). Nesse contexto, a escola é um dos principais ambientes para propagar novos valores e atitudes às crianças em formação e o desenvolvimento sobre a importância da EA (RODRIGUES et al., 2010). Pelicioni (2002) afirma que é viável que a EA possibilite a realização de um trabalho de intervenção sistemático, planejado e controlado em diversas áreas, sendo a escola o espaço propício para a abordagem desta temática, pois é nela que, indubitavelmente, deve-se iniciar esse processo.

A EA visa desenvolver nas pessoas a consciência dos problemas ambientais e incentivá-las a buscarem soluções para estes problemas, promovendo mudanças de comportamento e é nesse sentido, que a percepção ambiental dos professores e demais integrantes do corpo escolar é de grande relevância para os alunos (AMORIM; SILVA, 2021).

Segundo a Lei $\mathrm{n}^{\circ}$ 9.795/1999, entende-se por EA os processos por meio dos quais o indivíduo e a coletividade constroem valores sociais, conhecimentos, habilidades, atitudes e competências voltadas para a conservação do meio ambiente, bem de uso comum do povo e essencial à qualidade de vida e sustentabilidade (BRASIL, 1999). As instituições de ensino já estão conscientes que precisam trabalhar a problemática ambiental e muitas iniciativas têm sido desenvolvidas em torno desta questão, pois já foi incorporada à temática do meio ambiente nos sistemas de ensino como tema transversal dos currículos escolares, permeando toda a prática educacional (MEDEIROS et al., 2011).

A percepção de cada indivíduo sobre o ambiente faz parte do conhecimento que procuramos atualmente, salientando e estimulando uma maior reflexão sobre a importância da natureza para a sobrevivência de todos os seres vivos (MENEZES; BERTOSSI, 2011).

A interferência das ações humanas na natureza é notória e tem adquirido proporções preocupantes, incidindo de maneira nefasta em sua própria condição, na qualidade de vida do 
ser humano e na sobrevivência de futuras gerações (PEREIRA et al., 2013). Pinheiro et al. (2020) relata sua experiência com diferentes metodologias de ensino para contribuição do ensino de ecologia e conservação e EA, sendo diversas metodologias alternativas que podem se tornar ferramentas importantes para sensibilização e conscientização voltadas à conservação e importância de recursos naturais.

O objetivo foi relatar a aplicação da EA na rotina de docentes e discentes em uma escola de ensino fundamental.

\section{Metodologia}

\section{Local da pesquisa}

O trabalho foi executado em uma escola de ensino fundamental da rede pública de ensino do município de São Sebastião - AL (Figura 1). O estudo contou com a participação de alunos de uma turma de $8^{\circ}$ ano, com 40 discentes e 07 docentes da escola das disciplinas de ciências, matemática, língua portuguesa, história, geografia, língua inglesa, ensino religioso e artes. Os participantes desta pesquisa incluíam apenas alunos e professores do turno vespertino. O período de realização das pesquisas ocorreu durante o mês de agosto de 2019.

Figura 1. Localização do município de São Sebastião - AL.

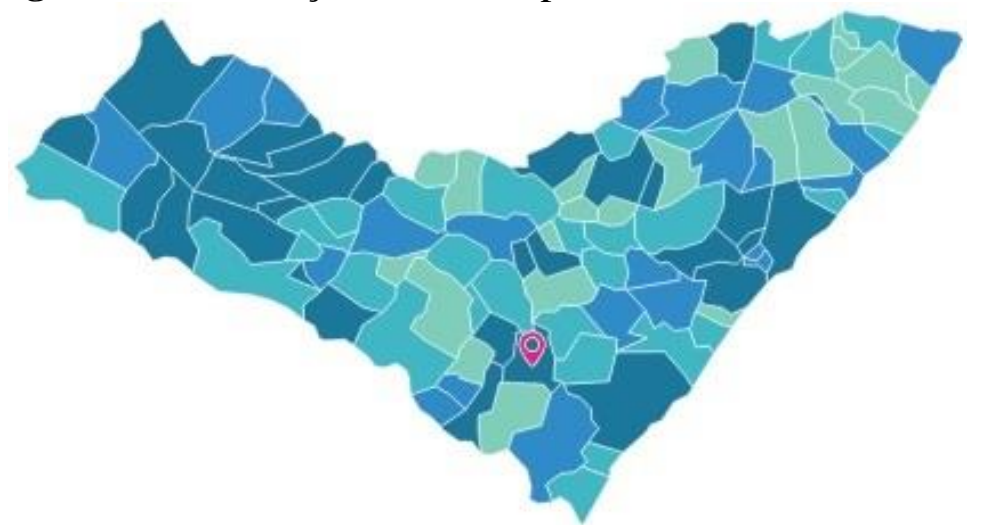

Fonte: IBGE (2021). 


\section{Coleta e análise dos dados}

O presente trabalho define-se como uma pesquisa quantitativa, executada por meio da aplicação de dois questionários (apêndices 1 e 2) para os discentes e docentes, contendo questões de natureza objetiva e subjetiva sobre o conhecimento dos alunos e dos professores referentes a Educação Ambiental.

Um questionário destinado aos discentes e outro questionário foi aplicado aos docentes cada questionário foi composto por 06 questões.

Os resultados dos questionários foram tabulados e analisados por meio do Software Microsoft Office Excel Professional Plus (2019).

\section{Resultados e discussão}

\section{Percepção dos discentes sobre EA}

Foi verificado o interesse dos discentes em assuntos relacionados ao meio ambiente, onde $67 \%$ dos alunos apresentaram interesse em assuntos da temática, $20 \%$ não demonstraram interesse, observando assim, que a maioria dos discentes apresentam interesse nos assuntos relacionados a EA.

Para $55 \%$ dos alunos responderam que acreditam que os recursos naturais (especialmente fauna e flora) são finitos e podem ficar escassos, 33\% dos discentes permaneceram neutros quando a disponibilidade dos recursos, mostrando uma variação mista de visão sobre os recursos naturais disponíveis para a humanidade.

Cerca de $75 \%$ dos discentes afirmaram contribuir em relação ao meio ambiente, outros $15 \%$ ficaram em dúvida do que tratava esta contribuição para o meio ambiente.

Apesar de uma quantidade considerável de discentes acreditar que os recursos não são finitos e terem dúvida sobre, $88 \%$ dos discentes acreditam que ações de natureza antrópica podem nos afetar, este resultado foi superior ao da exploração dos recursos limitados da fauna e flora, mas demonstra a noção de saber que ações antrópicas de inúmeras naturezas podem afetar ao meio ambiente.

Em relação às questões 5 e 6,70\% dos alunos já tiveram contato, de alguma maneira, com assuntos ligados à EA, enquanto $87 \%$ afirmam ter participado de atividades 
Revista Ambientale

Revista da Universidade Estadual de Alagoas/UNEAL

e-ISSN 2318-454X, Ano 13, Vol. 13 (3), 2021

https://doi.org/10.48180/ambientale.v13i3.313

ligadas à EA, apesar disto, se percebe que algumas questões, como as de recursos naturais, como fauna e flora, por exemplo, não foram trabalhados de maneira aprofundada.

\section{Percepção dos professores sobre EA}

Quando questionados, $71 \%$ dos docentes afirmaram que utilizam exemplos de EA em seu cotidiano escolar, enquanto $29 \%$ não utilizam.

Cerca de $86 \%$ dos docentes afirmaram que a EA deve ser abordada em aulas e projetos pedagógicos, enquanto $14 \%$ não veem necessidade desta abordagem, a porcentagem dos docentes que utilizam exemplos de EA é próxima aos que afirmam a importância de sua abordagem.

Quanto a frequência de abordagem da EA em suas disciplinas, $71 \%$ dos docentes afirmaram que aborda com frequência e $29 \%$ abordam em caso de necessidade.

Os docentes participantes afirmaram que EA deve ser abordada em todas as disciplinas, correspondendo a uma porcentagem de $100 \%$.

Cerca de 55\% dos docentes afirmaram se informar sobre a temática ambiental na TV, outros meios de obtenção foram com revistas e artigos científicos (Figura 2A).

Para 55\% dos docentes afirmaram que a EA é trabalhada em aulas, principalmente e, $36 \%$ afirmaram que a EA é trabalhada em projetos pedagógicos (Figura 2B).

Figura 2. Porcentagem de resposta dos docentes participantes da intervenção sobre a percepção de EA (A e B).
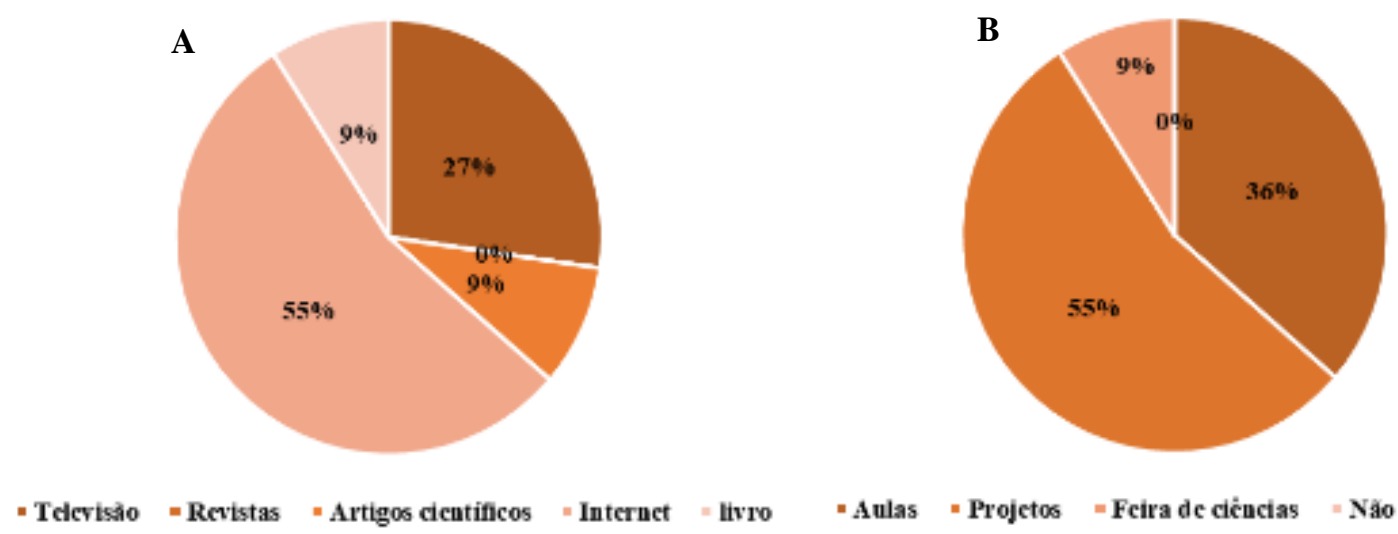

Fonte: Dos Santos (2019). 


\section{Revista Ambientale \\ Revista da Universidade Estadual de Alagoas/UNEAL \\ e-ISSN 2318-454X, Ano 13, Vol. 13 (3), 2021 \\ https://doi.org/10.48180/ambientale.v13i3.313}

Em estudo com enfoque semelhante, foi possível notar que a maior parte dos alunos sabe da importância de separar o lixo, no entanto, muitos ainda destinam incorretamente os resíduos, quer sejam de origem orgânica, quer seja de natureza industrial, como pilhas e baterias. Foi perceptível que os alunos possuíam alguma sensibilidade sobre a importância da Educação Ambiental e da coleta seletiva, contudo, não foi observada ainda a consciência no que tange a ações efetivas relativas a essa temática (FERREIRA et al., 2020).

A importância de duas ferramentas para conscientização de discentes da educação básica, sendo elas a agroecologia e a EA. As práticas realizadas para o trabalho coletivo durante todo o processo de criação de uma horta escolar (SILVA et al. 2020). Outro ponto presente foi a utilização e reciclagem de materiais que originalmente seriam descartados. Técnicas e atividades que utilizem vieses de aprimoramento de trabalho coletivo e reutilização de materiais com destinação incerta são outras formas de implementar a EA em escolas (SILVA et al., 2020).

Atividades realizadas em escola de educação básica, voltadas a conservação da fauna e flora para avaliar o grau de conhecimento dos alunos voltados às temáticas, os autores conseguiram verificar que os alunos já possuíam conhecimentos sobre as temáticas antes mesmo da realização da intervenção, este mesmo fenômeno foi observado neste estudo (SANTOS et al., 2019).

Para que os alunos continuem aprendendo sempre, é preciso instrumentalizá-los com procedimentos que os coloquem à prova e desenvolvam sua capacidade de autonomia (NOGUEIRA, 2008).

Em um estudo de intervenção, foi observado que os professores reconheceram a importância da Educação Ambiental, mas sua aplicabilidade limitou-se a apresentação de conceitos. Além disso, a partir das respostas dadas pelos professores entrevistados, percebeu-se que a aplicabilidade da EA nas escolas é comprometida por uma série de dificuldades e desafios que, muitas vezes, perpassam o âmbito meramente escolar, ao passo que as políticas públicas de gestão não oferecem subsídios suficientes para que tanto as escolas (ALENCAR \& SILVA, 2020).

O papel do professor na atualidade é o de se arriscar, buscar sempre métodos e novas formas que agreguem participação dos alunos na formação de sujeitos críticos e 
Revista Ambientale

Revista da Universidade Estadual de Alagoas/UNEAL e-ISSN 2318-454X, Ano 13, Vol. 13 (3), 2021

https://doi.org/10.48180/ambientale.v13i3.313

conscientes, indivíduos capazes de transformar o meio em que estão inseridos (CHERUBINI, 2013).

\section{Considerações finais}

Com a realização da intervenção, foi observado que os discentes e docentes da instituição possuíam senso básico sobre EA e sua importância para a formação do ser crítico social.

\section{Conflitos de interesse}

Os autores deste manuscrito não declararam conflitos de interesse. 
Revista Ambientale

Revista da Universidade Estadual de Alagoas/UNEAL e-ISSN 2318-454X, Ano 13, Vol. 13 (3), 2021

https://doi.org/10.48180/ambientale.v13i3.313

\section{Referências bibliográficas}

ALENCAR, V. E. M.; SILVA, R. N. Educação ambiental na percepção de professores de escolas públicas, localizadas em Jaramataia/AL, Brasil. Diversitas Journal, v. 5, n. 3, p. 1658-1670, 2020.

BRASIL. Lei $\mathrm{n}^{\circ}$ 9.795, de 27 de abril de 1999. Dispõe sobre a educação ambiental, institui a Política Nacional de Educação Ambiental e dá outras providências, 1999 Disponível em: 〈http://www.planalto.gov.br/ccivil_03/leis/19795.htm>. Acesso em: 29 mar. 2021.

CHERUBINI, I. C. B. A educação ambiental e a interdisciplinaridade em sala de aula. In: EPEA - Encontro Paranaense de Educação Ambiental, 14, 2013, Cascavel. Anais... Cascavel: Universidade Federal do Paraná, 2013.

DA SILVA, L. F.; BARROS, R. P.; PINHEIRO, R. A.; SILVA, J. E.; CABRAL, M. J. S.; DE LIMA, J. S. Agroecologia e horta escolar como ferramentas de educação ambiental e produção de alimentos naturais. Diversitas Journal, v. 5, n. 1, p. 27-33, 2020.

FERREIRA, E. E.; ALMEIDA, J. J. P.; SILVA, L. E. B.; DOS SANTOS LIMA, M. L.; DA SILVA, R. N. Coleta seletiva: concepção de alunos do ensino fundamental de uma escola pública do município de Arapiraca-AL. Diversitas Journal, v.5, n.4, p. 26762691, 2020.

MEDEIROS, A. B.; MENDONÇA, M. J. S. L.; SOUSA, G. L.; OLIVEIRA, I. P. A. Importância da educação ambiental na escola nas séries iniciais. Revista Eletrônica Faculdade Montes Belos, v. 4, n. 1, p. 1 - 17, 2011.

MENEZES, J. P. C.; BERTOSSI, A. P. A. Percepção ambiental dos produtores agrícolas e qualidade da água em propriedades rurais. REMEA-Revista Eletrônica do Mestrado em Educação Ambiental, v. 27, 2011.

NOGUEIRA, N. R. Pedagogia dos projetos: etapas, papéis e atores. $4^{a}$ ed. São Paulo: Editora Érica, 2008.

PADIAL, K. Coleta Seletiva - Conheça o lixo produzido pela escola e garanta o descarte correto. Revista Gestão Escolar (Editora Abril). Abril/maio de 2013. Ano V $\mathrm{n}^{\circ} 25$.

PEREIRA, E. G. C.; DA FONTOURA, H. A.; DE LA ROCQUE, L. R. Educação ambiental e os documentos oficiais de ensino: encontros e desencontros. Revista de Educação, Ciências e Matemática, v. 3, n. 3, 2013. 
Revista Ambientale

Revista da Universidade Estadual de Alagoas/UNEAL e-ISSN 2318-454X, Ano 13, Vol. 13 (3), 2021

https://doi.org/10.48180/ambientale.v13i3.313

PINHEIRO, R. A.; CABRAL, M. J. S.; SANTOS, J. A.; BARROS, R. P. Field classes as an improvement strategy for the discipline of Ecology and Conservation. Revista Ambientale, v. 12, n. 3, p. 76-87, 2020.

RODRIGUES, S.; SILVEIRA, Á. S. B.; PORTELA, I. P.; LEÃO, A. L. S. Projeto Educação Ambiental no Contexto Escolar. Revista Conhecimento Online, v. 2, p. 161$168,2010$.

SANTOS, R. L. V.; SILVA, L. E. B.; LIMA, L. L. C.; PINHEIRO, R. A.; SOUZA, WILLIAN C. L.; SOBRINHO, F. S. L.; SILVA, M. C. S. Educação Ambiental na Conservação da Fauna (Anuros e Tropidurus) e Flora em Arapiraca, Alagoas ANAIS DO $70^{\circ}$ CONGRESSO NACIONAL DE BOTÂNICA $36^{\circ}$ Reunião Nordestina de Botânica. P. 809 - 810. Link:

https://www.researchgate.net/publication/350591557_Germinacao_e_desenvolvimento inicial_de_mudas_de_girassol_mexicano_Tithonia_rotundifolia_Mill_SF_Blake_Astera ceae_em_diferentes_fontes_de_materia_organica.

SILVA, J. E.; ROZENDO, J. M. A.; PINHEIRO, R. A.; LIRA, T. P. S.; CABRAL, M. J. S.; BARROS, R. P. Percepção de alunos do ensino fundamental sobre a conservação de insetos polinizadores e construção de um jardim floral. Diversitas Journal, v. 5, n. 4, p. 2520-2527, 2020. 


\section{APÊNDICE 1: QUESTIONÁRIO PARA OS ALUNOS, UTILIZADO NA PESQUISA}

1. Você se interessa pelo meio ambiente?

Sim ( ) ( ) Não

2. Você acha que algum dia os recursos ambientais, fauna e flora, irão acabar? $\operatorname{Sim}($ )

3. Você contribui de alguma forma com a conservação do meio ambiente? $\operatorname{Sim}($ )

( ) Não

4. Você acha que os danos causados ao meio ambiente podem nos afetar de alguma forma?

Sim ( ) ( ) Não Não sei ( )

5. Você já ouviu falar sobre Educação Ambiental?

Sim ( ) ( ) Não

6. Sobre a Educação Ambiental, com que frequência seus professores a abordam?

( ) Frequentemente ( ) Raramente ( ) Não sei 


\section{APÊNDICE 2: QUESTIONÁRIO PARA OS PROFESSORES, UTILIZADO NA PESQUISA}

1. Você utiliza exemplos do cotidiano em suas aulas sobre a temática ambiental? $\operatorname{Sim}($ ) Não ( )

2. A Educação Ambiental deve ser trabalhada em aulas e projetos de Ciências? $\operatorname{Sim}($ ) Não ( )

3. Você aborda EA com frequência nas aulas?

( ) $\operatorname{Sim}$ ( ) Não

4. Na escola, a Educação Ambiental deveria se trabalhar com mais frequência e por todas as disciplinas?

$\operatorname{Sim}($ ) Não ( )

5. Qual meio de comunicação você tem acesso a divulgações sobre a temática ambiental?
( ) Televisão
( ) Revistas
( ) Artigos científicos
( ) Internet
( ) Livro

6. De que forma a Educação Ambiental é trabalhada na escola?
A. ( ) Aulas.
B. ( ) Projetos.
C. ( ) Feira de Ciências.
D. ( ) Não é trabalhada. 